\title{
Pengenalan Motif Songket Palembang Menggunakan Deteksi Tepi Canny, PCA dan KNN
}

\author{
Moh. Arie Hasan \\ Sekolah Tinggi Manajemen Informatika dan Komputer \\ Nusa Mandiri \\ Jakarta, Indonesia \\ 14002250@nusamandiri.ac.id
}

\author{
Dewi Yanti Liliana \\ Politeknik Negeri Jakarta, \\ Kampus Universitas Indonesia \\ Depok, Indonesia \\ dewiyanti.liliana@tik.pnj.ac.id
}

Diterima : 21 Februari 2020. Disetujui: 9 Mei 2020. Dipublikasikan: 15 Mei 2020

\begin{abstract}
Palembang Songket is one type of songket characteristic of Indonesian culture which has various types of motifs. Various types of motifs make it difficult for ordinary people to recognize songket that has a similar motif. This study aims to identify 2 types of Palembang songket motifs, namely bintang berante and nampan perak. The classification process will go through 3 stages, namely preprocessing, feature extraction and classification. The preprocess changes the color image of songket into grayscale image. In the feature extraction stage, the grayscale image is increased in contrast with histogram equalization and then uses Canny edge detection to obtain patterns from the songket motif. The extraction results are then grouped and labeled according to their motives for further classification using Principal Component Analysis (PCA) and $k$-Nearest Neighbor (KNN). Previous studies have resulted in an accuracy of $90.5 \%$ for 5 types of motifs using the back propagation algorithm. From the trial results obtained an accuracy value reached $91.67 \%$.
\end{abstract}

Keywords: songket; canny edge; $P C A ; K N N$

Abstrak - Songket Palembang merupakan salah satu jenis songket ciri khas budaya Indonesia yang memiliki berbagai jenis motif. Jenis motif yang beragam menyulitkan orang awam untuk mengenali songket yang memiliki kemiripan motif. Penelitian ini bertujuan untuk mengenali 2 jenis motif Songket Palembang, yaitu songket bintang berante dan nampan perak. Proses klasifikasi akan melalui 3 tahap yaitu preprocessing, feature extraction dan klasifikasi. Preproses mengubah citra warna songket menjadi citra grayscale. Pada tahap ekstraksi fitur, citra grayscale ditingkatkan kontrasnya dengan histogram equalization dan kemudian menggunakan Deteksi Tepi Canny untuk mendapatkan pola dari motif songket tersebut. Hasil ekstraksi kemudian dikelompokkan dan diberi label sesuai motifnya untuk selanjutnya diklasifikasikan menggunakan Principal Component Analysis (PCA) dan k-Nearest Neighbor (KNN). Penelitian sebelumnya telah menghasilkan akurasi sebesar $90,5 \%$ untuk 5 jenis motif dengan menggunakan algoritma propagasi balik. Dari hasil uji coba diperoleh nilai akurasi mencapai $91,67 \%$.

Kata Kunci : songket; tepi Canny; PCA; KNN

\section{PENDAHULUAN}

Songket merupakan jenis kain tenunan tradisional di Indonesia, Malaysia, dan Brunei. Songket ditenun menggunakan tangan dengan benang emas dan perak, serta pada umumnya dikenakan pada acara-acara resmi. Songket Palembang merupakan jenis songket yang terkenal dibandingkan kain tenunan sejenis dari daerah lainnya. Dalam satu jenis songket memiliki beberapa bagian, namun untuk mengenali satu songket dengan songket yang lain berdasarkan motifnya bisa dilihat pada kembang tengahnya.

Secara garis besar, motif Songket Palembang terdiri dari 7 (tujuh) bagian, yaitu secara berurutan dari motif terluar hingga terdalam dikelilingi tretes, umpak ujung, pengapit, tawur, umpak bangkot, ombak, dan kembang tengah atau motif inti [1]. Pada penelitian ini diambil dua motif Songket
Palembang yaitu songket bintang berante dan nampan perak.

Proses pengenalan sebuah pola motif songket dibagi menjadi 3 tahap. Tahap pertama adalah preprocessing yang mengubah citra songket yang berwarna menjadi citra songket grayscale. Tahap berikutnya adalah tahap feature extraction. Pada tahap ini data kemudian dirubah menjadi bentuk pola dengan menggunakan algoritma Deteksi Tepi Canny. Pada penelitian sebelumnya yang dilakukan oleh Imelda Dua Reja, menyimpulkan bahwa penggunaan Deteksi Tepi Canny untuk memisahkan gambar asli dengan background mendapatkan hasil yang paling baik, sehingga untuk preprocessing dalam penelitian ini menggunakan algoritma Deteksi Tepi Canny [2]. Algoritma ini memberikan tingkat kesalahan rendah, melokalisasi titik-titik tepi (jarak piksel-piksel tepi yang ditemukan deteksi dan tepi sesungguhnya sangat pendek), dan hanya memberikan satu tanggapan untuk satu tepi [3]. 
Tahap terakhir adalah tahap klasifikasi songket menggunakan metode $k$-Nearest Neighbor.

Penelitian ini terdiri dari empat bagian, yaitu Bab I pendahuluan yang berisi latar belakang permasalahan yang mendasari penelitian dan tujuan penelitian. Bab II merupakan metode penelitian yang mencakup pemilihan dataset dan metode yang digunakan dalam melakukan penelitian. Bab III berisi proses pengujian data dan hasil penelitian yang dilakukan. Bab IV merupakan kesimpulan yang menjelaskan kesimpulan yang didapatkan dari hasil penelitian dan saran bagi penelitian selanjutnya.

\section{METODE PENELITIAN}

Penelitian sebelumnya yang telah dilakukan adalah menggunakan Deteksi Tepi Canny dan $k$ Nearest Neighbor untuk pengenalan motif batik [2] dengan akurasi $66,67 \%$, pengenalan motif batik Indonesia menggunakan Deteksi Tepi Canny dan template matching [3] memperoleh akurasi 89,44\%, dan pengenalan motif Songket Palembang menggunakan algoritma propagasi balik [1] menghasilkan akurasi sebesar 90,5\%.

\section{A. Dataset}

Data yang digunakan pada penelitian ini terdiri dari 52 citra gambar Songket Palembang yang terdiri dari 26 data latih citra songket bintang berante dan 26 data latih citra songket nampan perak. Data uji terdiri dari 6 citra songket bintang berante dan 6 citra songket nampan perak [1]. Contoh citra kedua jenis songket ini dapat dilihat pada Gambar 1.

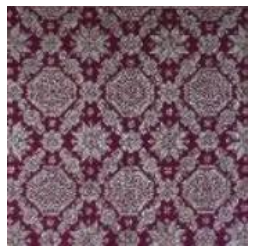

(a)

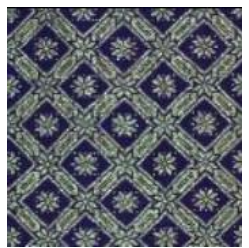

(b)
Gambar 1. Songket Bintang Berante (a), dan Songket Nampan Perak (b)

\section{B. Metode}

Proses pengenalan pola akan melewati beberapa tahapan proses dapat dilihat pada Gambar 2.

Gambar 2 menunjukkan bahwa metode yang dilakukan untuk klasifikasi jenis citra Songket Palembang dimulai dari input citra songket kemudian dilakukan preprocessing citra untuk mengubah citra menjadi grayscale. Berikutnya adalah melakukan histogram equalization untuk meningkatkan kualitas citra. Selanjutnya proses ekstraksi fitur citra songket. Hasil ekstraksi fitur yang telah diperoleh dikonversi menjadi principal component. Langkah terakhir adalah melakukan klasifikasi dengan algoritma KNN menentukan kedua jenis citra songket.

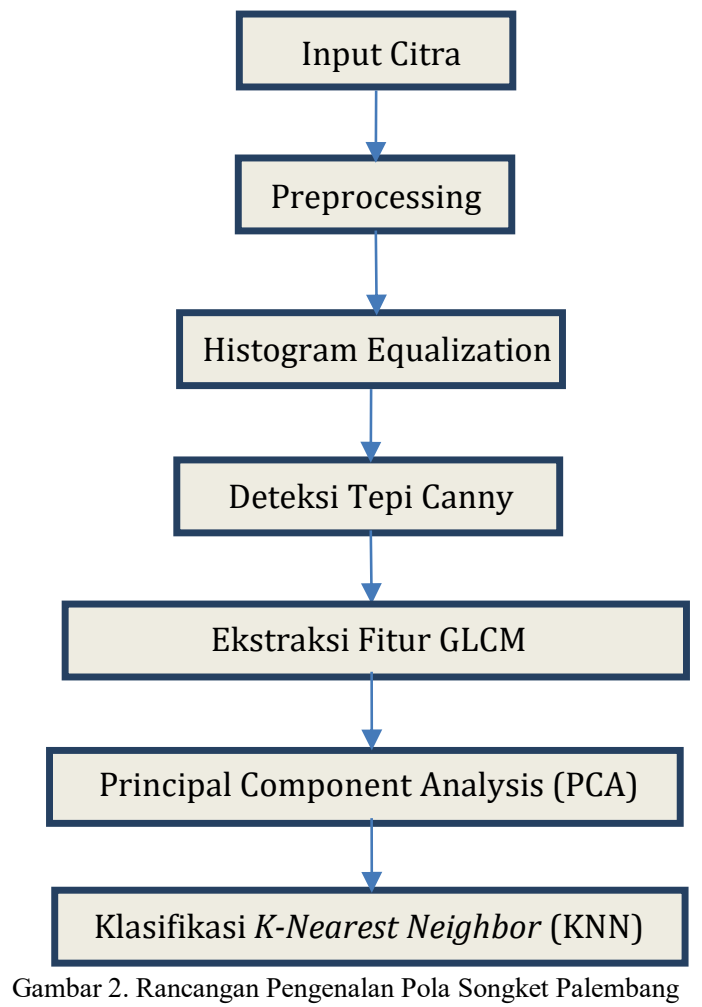

\section{Input Citra RGB}

Ruang warna RGB banyak digunakan dan biasanya merupakan ruang warna default untuk menyimpan dan merepresentasikan gambar digital. Kita bisa mendapatkan ruang warna lain dari transformasi RGB atau non-linear. Ruang warna RGB adalah ruang warna yang digunakan oleh komputer, kartu grafis dan monitor atau LCD [4]. Proses ini bertujuan untuk menampilkan ruang warna RGB (Red, Green, Blue) dari citra yang dikelola.

Rumus RGB :

$$
\begin{aligned}
& r=R /(R+G+B) \\
& g=G /(R+G+B) \\
& b=B /(R+G+B)
\end{aligned}
$$

dimana r merupakan nilai Red, g nilai Green, dan B nilai Blue.

\section{Preprocessing}

Tujuan dari preprosesing adalah untuk mempersiapkan citra songket agar dapat diproses untuk tahap selanjutnya. Pada tahap ini citra hasil scan akan di resize (merubah ukuran citra) menjadi 128x128, kemudian mengubah citra warna menjadi citra grayscale. Proses untuk mendapatkan citra 
grayscale dapat dilakukan dengan menggunakan persamaan 4.

$$
\text { grayscale }=(\text { Red }+ \text { Green }+ \text { Blue }) / 3
$$

Data yang telah dirubah menjadi grayscale nantinya hanya akan memiliki satu nilai untuk setiap pikselnya. Dengan menggunakan nilai yang ada ini nantinya gambar-gambar akan diolah. Tahap ekstraksi fitur akan melalui 2 tahapan diantaranya

\begin{tabular}{|l|l|l|l|l|}
\hline 2 & 4 & 5 & 4 & 2 \\
\hline 4 & 9 & 12 & 9 & 4 \\
\hline 5 & 12 & 15 & 12 & 5 \\
\hline 4 & 9 & 12 & 9 & 4 \\
\hline 2 & 4 & 5 & 4 & 2 \\
\hline
\end{tabular}

meningkatkan kontras dengan menggunakan histogram equalization dan menentukan batas tepi dari setiap citra menggunakan algoritma Deteksi Tepi Canny [2].

\section{Histogram Equalization}

Histogram Equalization (HE) merupakan teknik yang digunakan untuk mengatur intensitas suatu citra dengan meningkatkan nilai kontras. Cara kerja $\mathrm{HE}$ adalah dengan meratakan derajat histogram dari setiap sumbu warna. Prinsip kerjanya sangat sederhana, yaitu dengan membuat frekuensi warna lebih merata dari batas bawah ke batas atas sehingga tidak ada bagian histogram yang terlalu dominan.

Di sisi lain, histogram akan membuat persebaran kumulatif gray values (dari paling gelap ke paling terang) menjadi merata dan membentuk persamaan $\mathrm{X}=\mathrm{Y}$ [5]. Pendekatan yang dilakukan adalah untuk mempersempit aras keabuan pada daerah yang berpiksel sedikit dan mendapatkan aras keabuan yang lebih luas pada daerah yang memiliki banyak piksel yang memiliki efek dapat meningkatkan kontras secara menyeluruh [6].

Persamaan yang digunakan untuk meningkatkan kontras dengan menggunakan histogram equalization dapat dilakukan dengan menggunakan persamaan (5)

$$
S_{i}=\frac{(L-1)}{n} \sum_{n_{i}=0}^{i} n_{i}
$$

dimana :

$\mathrm{ni}=$ jumlah piksel yang memiliki derajat keabuan $\mathrm{i}$ $\mathrm{n}=$ jumlah seluruh piksel dalam citra

\section{Deteksi Tepi Canny}

Deteksi Tepi Canny memiliki langkah langkah sebagai berikut [7]:

\section{Smoothing}

Langkah pertama dalam Deteksi Tepi dengan menggunakan operator Canny adalah melakukan smoothing terhadap citra dengan tujuan untuk mengurangi respon sistem terhadap noise serta melakukan kontrol terhadap detail yang muncul pada tepi citra. Smoothing dilakukan dengan mengkonvolusi citra dengan operator Gaussian $\mathrm{g}(\mathrm{x}, \mathrm{y})$. Konvolusi itu sendiri adalah perkalian antara duah buah fungsi $\mathrm{f}(\mathrm{x}, \mathrm{y})$ dan $\mathrm{g}(\mathrm{x}, \mathrm{y})$. Pada filter Gaussian, nilai intensitas setiap piksel diganti dengan rata-rata dari nilai pembobotan untuk setiap piksel-piksel tetangganya dan piksel itu sendiri.

Piksel tetangga adalah piksel yang berada disekeliling piksel yang dimaksud. Jumlah tetangga yang dilibatkan tergantung pada filter yang dirancang. Filter Gaussian memiliki rumus matematika sebagai berikut:

$$
G(x, y)=\frac{1}{159}
$$

\section{Finding Gradients}

Algoritma Deteksi Tepi Canny pada dasarnya menemukan sisi yang memiliki perubahan intensitas paling tinggi dari suatu citra. Daerah ini ditemukan dengan menentukan gradien dari gambar tersebut. Gradien pada setiap piksel pada gambar dihaluskan dengan menerapkan operator Sobel. Langkah pertama adalah memperkirakan gradien di arah $\mathrm{x}$ dan y dengan menggunakan kernel pada persamaan berikut :

$$
\begin{aligned}
& \mathrm{K} \mathrm{Gx}=\left[\begin{array}{lll}
-1 & 0 & +1 \\
-2 & 0 & +2 \\
-1 & 0 & +1
\end{array}\right] \\
& \mathrm{K} G y=\left[\begin{array}{ccc}
1 & 2 & 1 \\
0 & 0 & 0 \\
-1 & -2 & -1
\end{array}\right]
\end{aligned}
$$

Kekuatan tepi (magnitudo gradient) dapat ditentukan sebagai jarak Euclidean yang diukur dengan menggunakan hukum Phytagoras, seperti pada persamaan :

$$
\mathrm{D}=\left|\mathrm{D}_{\mathrm{x}}(\mathrm{x}, \mathrm{y})+\mathrm{D}_{\mathrm{y}}(\mathrm{x}, \mathrm{y})\right|
$$

Untuk menentukan tepian sebenarnya, arah tepian harus ditentukan dan disimpan dengan menggunakan persamaan :

$$
\ominus=\arctan \frac{D y(x, y)}{D x(x, y)}
$$

\section{Non Maximus Suppression}

Pada langkah ini bertujuan membuang potensi gradient di suatu piksel dari kandidat tepi jika piksel tersebut bukan merupakan maksimal local pada arah tepi di posisi piksel tersebut. Oleh karena itu dibuat dengan logika sebagai berikut: If $\theta(\mathrm{x}, \mathrm{y})=0^{\wedge} \mathrm{o}$, piksel $(\mathrm{x}+1, \mathrm{y}),(\mathrm{x}, \mathrm{y})$ dan $(\mathrm{x}-1, \mathrm{y})$ diperiksa 
If $\theta(\mathrm{x}, \mathrm{y})=\llbracket 90 \rrbracket \wedge^{\mathrm{O}}$, piksel $(\mathrm{x}, \mathrm{y}+1),(\mathrm{x}, \mathrm{y})$ dan $(\mathrm{x}, \mathrm{y}-$ 1) diperiksa

If $\theta(\mathrm{x}, \mathrm{y})=\square 45 \rrbracket \wedge_{\mathrm{o}}$, piksel $(\mathrm{x}+1, \mathrm{y}+1),(\mathrm{x}, \mathrm{y})$ dan $(\mathrm{x}-1, \mathrm{y}-1)$ diperiksa

If $\theta(\mathrm{x}, \mathrm{y})=\llbracket 135 \rrbracket \wedge_{\mathrm{o}}$, piksel $(\mathrm{x}+1, \mathrm{y}-1),(\mathrm{x}, \mathrm{y})$ dan $(\mathrm{x}-1, \mathrm{y}+1)$ diperiksa

\section{Connection}

Tahap ini adalah klasifikasi tiap piksel apakah termasuk dalam kategori piksel tepi atau tidak dengan menerapkan double threshold (tentukan threshold bawah dan threshold atas). Implementasi yang digunakan sebagai berikut :

If piksel $(\mathrm{x}, \mathrm{y})$ memiliki gradient magnitude kurang dari t low bukan tepi.

If piksel $(\mathrm{x}, \mathrm{y})$ memiliki gradient magnitude lebih dari t_high dianggap tepi

If piksel $(x, y)$ memiliki gradient magnitude antara

$\mathrm{t}$ _low dan $\mathrm{t}$ _high dipertimbangkan sebagai tepi.

\section{GLCM}

Metode GLCM atau analisis tekstur merupakan salah satu metode untuk melakukan klasifikasi suatu citra, GLCM adalah matriks persegi yang dapat menjelaskan sifat - sifat tertentu dengan distribusi spasial. GLCM menggunakan perhitungan tekstur pada orde kedua. Pada orde pertama, pengukuran tekstur menggunakan perhitungan statistik didasarkan pada nilai piksel citra asli semata, seperti varians, dan tidak memperhatikan hubungan ketetanggaan piksel. Sedangkan hubungan antar pasangan dua piksel citra asli diperhitungkan pada orde kedua. Secara matematis, untuk mendapatkan nilaik piksel kookurensi seperti pada persamaan 2 dimana d adalah jarak antara dua piksel yaitu $(\mathrm{x} 1, \mathrm{y} 1)$ dan $(\mathrm{x} 2, \mathrm{y} 2)$

$$
P=\sum_{x-1}^{K} \sum_{y-1}^{K}\left\{\begin{array}{c}
1, i f I(x, y)=i \text { and } I\left(x+d_{x}, y+d_{y}\right)=j \\
0, \text { lainnya }
\end{array}\right\}
$$

Untuk memperoleh ciri statistic orde dua adalah dengan menghitung probabilitas hubungan ketetanggaan antara dua piksel pada jarak dan orientasi sudut tertentu. Setiap elemen dari GLCM adalah hubungan antara dua piksel dengan warna abu-abu i dan j dengan jarak d dan arah $\theta$ [8] .

\section{Principal Component Analysis (PCA)}

Analisis Komponen Utama digunakan untuk memproyeksikan atau mengubah suatu kumpulan data berukuran besar menjadi bentuk sajian data dengan ukuran yang lebih kecil. Transformasi PCA terhadap sebuah ruang data yang besar akan menghasilkan sejumlah vektor basis ortonormal dalam bentuk kumpulan vektor eigen dari suatu matriks kovarian tertentu yang dapat secara optimal menyajikan distribusi data [9]

Dalam hal ini digunakan metoda kovariansi dengan algoritma berikut :

Mengumpulkan data dalam bentuk matrix tingkatkeabuan $\mathrm{X}$ berukuran $\mathrm{M}$ x $\mathrm{N}$. Misalkan adalah vektor

$\mathrm{N} \mathrm{x} \mathrm{1.:}$

Menghitung rata-rata:

$$
x=\frac{1}{M} \sum_{i=1}^{M} x_{i}
$$

Menghitung selisih rata-rata:

$$
\Phi \mathrm{i}=\mathrm{xi}-\mathrm{x}
$$

Menentukan matriks kovarian Dari matriks $\mathrm{X}=[\Phi 1$ $\Phi 2$... ФM] (matriks NxM), Hitung kovarian:

$$
C=\frac{1}{M} \sum_{n=1}^{M} \phi_{n} \phi_{n}^{T}=X X^{T}
$$

Menentukan nilai karakteristik dan vektor karakteristik dari matrik kovarian

$$
\begin{aligned}
& \mathrm{C}: \lambda 1>\lambda 2>\ldots \ldots \ldots .>\lambda \mathrm{N} \\
& \text { dan } \\
& \mathrm{C}: \mathrm{u} 1, \mathrm{u} 2, \ldots \ldots \ldots \ldots \ldots, \mathrm{un}
\end{aligned}
$$

Mengurutkan vektor karakteristik $u$ dan nilai karakteristik $\lambda$ dalam matriks diagonal dalam urutan menurun sesuai dengan nilai peluang kumulatif terbesar untuk tiap vector karakteristik sehingga diperoleh nilai-nilai karakteristik yang dominan [10].

\section{K-Nearest Neighbor (KNN)}

Metode selanjutnya yaitu menggunakan algoritma K-Nearest Neighbor (KNN) untuk mengklasifikasi objek baru berdasarkan atribut dan training samples dimana hasil dari sampel uji yang baru diklasifikasikan berdasarkan mayoritas dari kategori pada KNN. Pada proses pengklasifikasian, tidak digunakan model apapun untuk dicocokkan dan hanya berdasarkan pada memori [11].

Prinsip kerja KNN yaitu mencari jarak terdekat antara data yang akan dievaluasi dengan $\mathrm{K}$ tetangga (neighbor) terdekatnya dalam data pelatihan. Data pelatihan diproyeksikan ke ruang berdimensi banyak, dimana masing-masing dimensi merepresentasikan fitur dari data. Ruang ini dibagi menjadi bagian-bagian berdasarkan klasifikasi data pelatihan. Sebuah titik pada ruang ini ditandai kelas c, jika kelas c merupakan klasifikasi yang paling banyak ditemui pada $\mathrm{k}$ buah tetangga terdekat titik tersebut. Dekat atau jauhnya tetangga biasanya dihitung berdasarkan jarak Euclidean dengan rumus sebagai berikut : 


$$
d_{i}=\sqrt{\sum_{i=1}^{p}\left(x_{2 i}-x_{1 i}\right)^{2}}
$$

Dengan $\mathrm{x} 1=$ sampel data, $\mathrm{x} 2=$ data $u \mathrm{uj}, \mathrm{i}=$ variabel data, dist $=$ jarak, $p=$ dimensi data. Pada fase pembelajaran, algoritma ini hanya melakukan penyimpanan vektor-vektor fitur dan klasifikasi dari data pembelajaran. Pada fase klasifikasi, fitur-fitur yang sama dihitung untuk data test. Jarak dari vektor yang baru ini terhadap seluruh vektor data pembelajaran dihitung, dan sejumlah $\mathrm{k}$ buah yang paling dekat diambil. Titik yang baru klasifikasinya diprediksikan termasuk pada klasifikasi terbanyak dari titik-titik tersebut. Nilai $\mathrm{k}$ yang terbaik untuk algoritma ini tergantung pada data. Umumnya, nilai $\mathrm{k}$ yang tinggi akan mengurangi efek noise pada klasifikasi, tetapi membuat batasan antara setiap klasifikasi menjadi lebih kabur [12].

\section{HASIL DAN PEMBAHASAN}

Proses awal dari klasifikasi jenis songket adalah input citra songket dari data latih dan dilakukan resize (merubah ukuran citra) menjadi $128 \times 128$, serta mengubah citra warna menjadi citra grayscale, seperti pada Gambar 3.

Langkah selanjutnya yaitu meningkatkan kontras citra dengan menggunakan teknik histogram equalization, seperti terlihat pada Gambar 4.

Setelah didapatkan citra hasil histogram equalization, dilakukan Deteksi Tepi Canny untuk memperhalus tampilan citra, seperti pada Gambar 5.

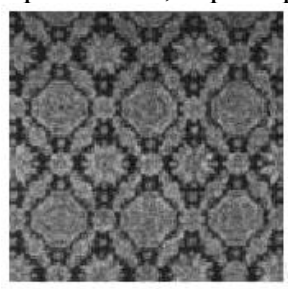

Gambar 3. Citra Grayscale

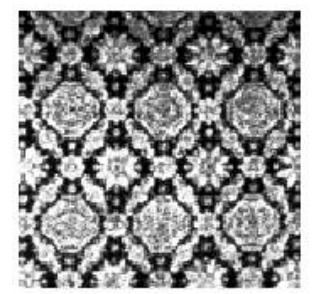

Gambar 4. Citra Hasil Histogram equalization

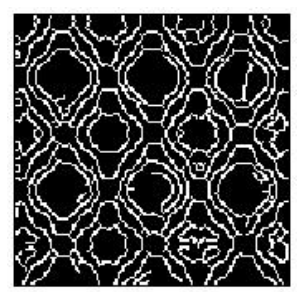

Gambar 5. Citra Hasil Deteksi Tepi Canny
Selanjutnya untuk mendapatkan akurasi dari klasifikasi jenis songket dilakukan pengujian dengan menggunakan aplikasi GUI menggunakan aplikasi Matlab. Aplikasi yang dirancang terdiri dari beberapa fungsi, yaitu input citra, citra grayscale, Deteksi Tepi Canny, ekstraksi ciri, dan proses menentukan hasil klasifikasi.

Proses pertama yang dilakukan adalah input citra songket yang akan dilakukan pengujian. Selanjutnya citra diubah menjadi citra grayscale. Citra grayscale kemudian dilakukan perbaikan dengan menggunakan histogram equalization. Proses berikutnya adalah melakukan Deteksi Tepi Canny dan ekstraksi fitur contrast, correlation, energy, homogeneity. Berikut tampilan Aplikasi GUI Matlab yang sudah dibuat :

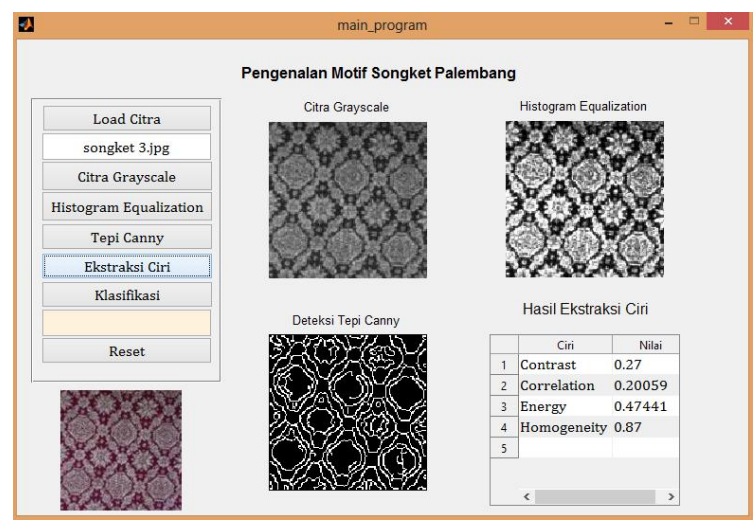

Gambar 6. Tampilan Aplikasi GUI Matlab Hasil Ekstraksi Ciri

Berdasarkan hasil ekstraksi fitur yang telah diperoleh, dilakukan proses untuk menentukan klasifikasi dengan menggunakan algoritma PCA dan KNN. Berikut merupakan tampilan GUI Matlab hasil klasifikasi untuk jenis songket bintang berante dan nampan perak:

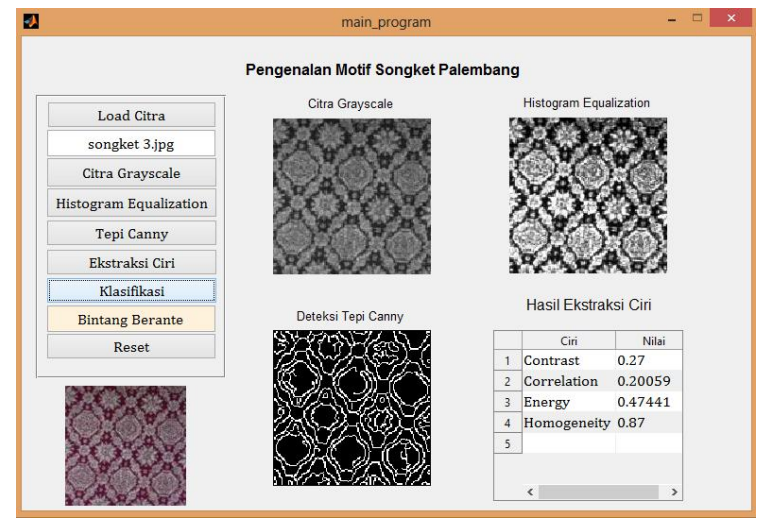

Gambar 7. Tampilan Aplikasi GUI Matlab Hasil Klasifikasi Jenis Songket Bintang Berante 


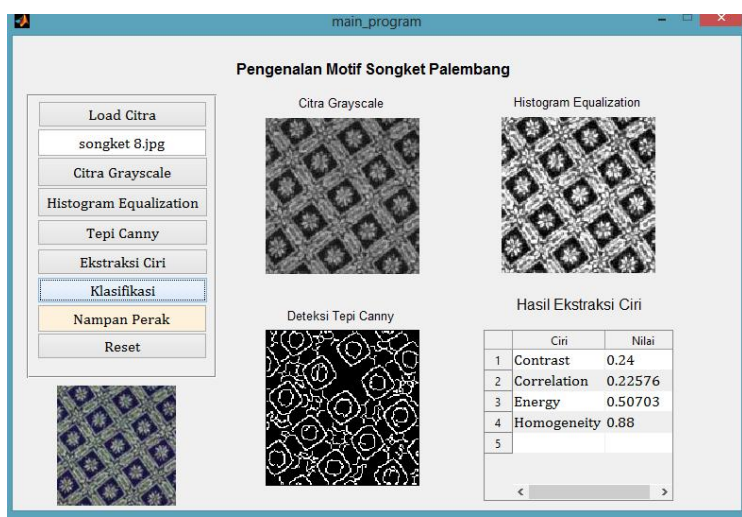

Gambar 8. Tampilan Aplikasi GUI Matlab Hasil Klasifikasi Jenis Songket Nampan Perak

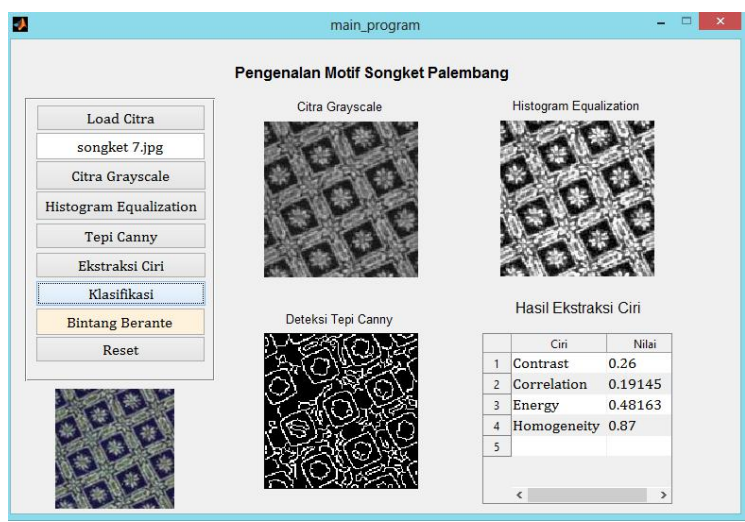

Gambar 9. Tampilan Aplikasi GUI Matlab Hasil Klasifikasi Jenis Songket Nampan Perak Yang Diklasifikasikan Menjadi Songket Bintang Berante

Hasil pengujian dilakukan terhadap data uji sejumlah 12 jenis songket dengan menggunakan Aplikasi GUI Matlab dapat dilihat pada TABEL I.

TABEL I. HASIL PENGOLAHAN CITRA JENIS SONGKET

\begin{tabular}{cccc}
\hline No. & Citra Uji & Kelas Asli & Kelas Keluaran \\
\hline 1 & Songket1.jpg & Bintang Berante & Bintang Berante \\
\hline 2 & Songket2.jpg & Bintang Berante & Bintang Berante \\
\hline 3 & Songket3.jpg & Bintang Berante & Bintang Berante \\
\hline 4 & Songket4.jpg & Bintang Berante & Bintang Berante \\
\hline 5 & Songket5.jpg & Bintang Berante & Bintang Berante \\
\hline 6 & Songket6.jpg & Bintang Berante & Bintang Berante \\
\hline 7 & Songket7.jpg & Nampan Perak & Bintang Berante \\
\hline 8 & Songket8.jpg & Nampan Perak & Nampan Perak \\
\hline 9 & Songket9.jpg & Nampan Perak & Nampan Perak \\
\hline 10 & Songket10.jpg & Nampan Perak & Nampan Perak \\
\hline 11 & Songket11.jpg & Nampan Perak & Nampan Perak \\
\hline 12 & Songket12.jpg & Nampan Perak & Nampan Perak \\
\hline & & &
\end{tabular}

Berdasarkan TABEL I, 11 songket berhasil diklasifikasikan sesuai dengan jenisnya, namun terdapat 1 songket nampan perak yang diklasifikasikan menjadi songket bintang berante. Hasil akhir akurasi pengujian jenis songket adalah sebesar 91,67\%, yang didapatkan dari 11 (jumlah benar) / 12 (jumlah data uji) *100\%. Besarnya nilai akurasi yang dihasilkan menunjukkan bahwa algoritma PCA dan KNN dapat diterapkan pada klasifikasi jenis songket.

\section{KESIMPULAN}

Penelitian ini mendapatkan hasil bahwa dari hasil proses klasifikasi pengolahan citra jenis songket bintang berante dan nampan perak diperoleh hasil akurasi sebesar 91,67\%. Dengan menggunakan algoritma Principal Component Analysis dan $K$ Nearest Neighbor dapat digunakan dalam proses klasifikasi jenis songket. Kualitas citra sangat berpengaruh terhadap hasil klasifikasi serta banyaknya data latih yang digunakan untuk mendapatkan hasil klasifikasi. Semakin banyak data latih yang digunakan maka semakin baik pula hasil akurasi klasifikasi jenis songket. Klasifikasi jenis songket masih menggunakan dua jenis songket yaitu bintang berante dan nampan perak. Disarankan untuk mengembangkan penelitian selanjutnya dengan menggunakan lebih dari dua jenis songket.

\section{REFERENSI}

[1] A. Riztyan and R. B. Dariska, "Analisis Pengenalan Motif Songket Palembang Menggunakan Algoritma Propagasi Balik," 2013.

[2] J. W. Yodha and A. W. Kurniawan, "Pengenalan Motif Batik Menggunakan Deteksi Tepi Canny dan K-Nearest Neighbor," Techno. com, vol. 13, no. 4, pp. 251-262, 2014.

[3] F. Flaurensia, T. Rismawan, and R. Hidayati, "Pengenalan Motif Batik Indonesia Menggunakan Deteksi Tepi Canny Dan Template Matching," Coding J. Komput. dan Apl., vol. 4, no. 2, 2016.

[4] S. Kolkur, D. Kalbande, P. Shimpi, ... C. B. preprint arXiv, and undefined 2017, "Human skin detection using RGB, HSV and YCbCr color models," arxiv.org.

[5] P. Pangestu, "Penerapan Histogram equalization pada Optical Character Recognition Preprocessing," Ultimatics, vol. VII, no. 1, pp. 27-34, 2015.

[6] M. F. Wafi, "Sistem Identifikasi Biometrik Finger Knuckle Print Menggunakan Histogram equalization dan Principal Component Analysis (PCA)," Bul. Inov. ICT Ilmu Komput., vol. 3, no. 1, 2016.

[7] J. W. Yodha and A. W. Kurniawan, "Pengenalan Motif Batik Menggunakan Deteksi Tepi Canny Dan K-Nearest Neighbor," Techno.COM, vol. 13, no. 4, November, pp. 251-262, 2014.

[8] M. Ramadhani, "Klasifikasi Jenis Jerawat Berdasarkan Tekstur dengan Menggunakan Metode GLCM," $e$ Proceding of Enggineering, vol. 5, no. 1, pp. 870-876, 2018.

[9] J. Muhammad and S. I. Isnanto Riza, "Identifikasi iris mata menggunakan metode analisis komponen utama dan perhitungan jarak euclidean," pp. 1-9.

[10] Herfina, "Pengenalan Pola Bentuk Bunga Menggunakan Principle Component Analysis," Semin. Nas. Teknol. Inf. dan Multimed., no. 7, pp. 25-30, 2013.

[11] F. Liantoni, "Klasifikasi Daun Dengan Perbaikan Fitur 
Citra Menggunakan Metode K-Nearest Neighbor," J. Ultim., vol. 7, no. 2, pp. 98-104, 2016.

[12] R. N. Whidhiasih, N. A. Wahanani, and S. Supriyanto, "Klasifikasi Buah Belimbing Berdasarkan Citra Red-GreenBlue Menggunakan Knn Dan Lda," Penelit. Ilmu Komput. Sist. Embed. dan Log., vol. 1, no. 1, pp. 29-35, 2013. 